\title{
Coping up of problems by children with learning disability
}

\author{
P. Neeraja and K. Anuradha
}

See end of the paper for authors' affiliations P. Neeraja

Department of Home Science, S.V.University, Tirupati (A.P.) India
Received: 20.10.2018; Revised: 19.04.2019; Accepted: 29.04.2019

-ABSTRACT : Children with learning disabilities have trouble taking in information through their senses and processing that information accurately to the brain. Usually they will receive scrambling information like a distorted radio signal or fuzzy television picture. Specific learning disability affects 5-15 per cent of school going children (Sunil et al., 2011). Both the individual and their family need to learn methods of coping with the effects of the disorder; they also need to learn how to cope with the disorder emotionally. Stress related to the disorder can accumulate, making the coping process difficult. Stigmas that friends/family/peers have about the learning disorder can also contribute to the stress level the individual feels. Learning disabilities are often present throughout the lifespan, so learning appropriate and effective methods of coping are essential to successful management of the disorder. The study sample were elementary school children selected from Hyderabad, Nellore and Chittoor districts of united state of Andhra Pradesh representing three regions of the state i.e. Rayalaseema, Costal region and Telangana. Total sample were 120 children with LD attending special education (60) and not attending special education (60). In this study found that the prevalence of learning disability was more among boys than girls and among first born children and had average intelligence. The prevalence was more in reading, writing and mathematics among children with learning disability. LD children who were attending special education classes had moderate coping up capacity of problems in different areas like home, school, emotional and social. Early identification of LD problems and early intervention help in bringing out better coping up capacity among children with LD.

KEY WORDS: Problems, Children, Learning disability

- HOW TO CITE THIS PAPER : Neeraja, P. and Anuradha, K. (2019). Coping up of problems by children with learning disability. Asian J. Home Sci., 14 (1) : 91-97, DOI: 10.15740/HAS/AJHS/14.1/91-97. Copyright@ 2019: Hind Agri-Horticultural Society. 